\title{
Effect of Fusariosis on the Metabolism of Phenolics
}

\section{Compounds of Date Palm Leaflets, Resistant and Sensitive to the Disease}

\author{
Saida Ouafi and Nicole Bounaga \\ Research Laboratory on Arid Zones (L.R.Z.A), Faculty of Biology (USTHB), Bab Ezzouar, Algiers 16111, Algéria
}

Received: March 1, 2012 / Published: April 20, 2012.

\begin{abstract}
Because of socio-economic importance of date palm in North Africa, the scientific community has always followed the progression of parasitic disease that affects it. The study was performed on population of thirty palm trees belonging to three cultivars of the oases of south-west Algeria TOUAT Gourara. The analytical protocol consists of a hot hydrochloric acid hydrolysis of $1 \mathrm{~g}$ of leaf material dried and ground. Structural analysis of compounds present in extracts was conducted by chromatographic and spectrophotometric techniques. Through the analysis of all HPLC profiles of phenolic acids, we have established three chemotypes: resistant with the highest heights, sensitive, with the lowest height, finally low sensitivity or tolerant with intermediate heights. The increased synthesis of C-glycoflavones, within diseased palms, can be seen as the first sign of plant response to fungal attack, or even as a defense mechanism so these flavonoids correspond to "pre-inhibitines". It has not been found qualitative differences between different cultivars studied. The merits of our work show a negative correlation between flavonoid content and the level of lignification in the date palm, suggests that the process of lignification is more rapid in resistant cultivars. We can say that there is a constitutive resistance.
\end{abstract}

Key words: Date palm tree, fusariose, chemotype, resistant, phenolic compounds.

\section{Introduction}

The date palm, Phoenix dactylifera L. is the only species to be adapted to the most arid regions of the planet. At the base of the diet of traditional agricultural societies of the Sahara, the date palm is probably for agriculture in desert regions the best source in the future. In Algeria, the park covers about 1 million hectares, almost all agricultural land areas lying below the isohyet 100 mm-year. The number of date palm tree is estimated at 17 million for one-third crop farming, mainly on the cultivar of date Deglet Nur, the other two thirds, producing 120,000 tons of dates of various cultivars, feed producers and the local market, Reported for the first time there are over 120

\footnotetext{
Corresponding author: Saida Ouafi, Ph.D., teacher-researcher, research field: phytochemistry of date palm. E-mail: Saida_ouafi@yahoo.fr.
}

years fusariosis date palm tree, caused by the fungus Fusarium oxysporum f.sp. albedinis identified by Malençon [1] or bayoud, attacks best cultivars and destroyed 10 million trees in Morocco and 3 million in Algeria. Present exclusively in these two countries, this disease constitutes a serious threat to date palm of the other countries of North Africa and the Middle East.

According to the work of Rahmania [2], Matheron and Benbadis [3], the penetration of Fusarium oxysporum $\mathrm{f}$ sp albedinis is through the roots and then invades the vascular elements of the palms causing the decay and the bleaching and death of affected tree from which the name of the disease "Bayoud".

The definition of flavone content of the species seemed to us interesting to acquire, since the "small molecules" are recognized both as genetic markers 
and as molecules of relationship. Initially, a flavone type cultivar was proposed, essentially based on the profile flavones/flavonols and opened the way to the taxonomy and infra specific genetic [4-7]. In this work, we present results on the physiology of polyphenols in response to infection by the Fusarium in order to find a possible relationship between metabolism of the parasite and that of date palm cultivars studied.

\section{Materials and Methods}

\subsection{Materials}

The study was conducted on population of thirty palm trees belonging to three cultivars of the oase of south-west Algeria TOUAT Gourara (rainfall below $30 \mathrm{~mm} /$ year). Harvesting of foliage (palm leaflets) was performed in November 2003.

\subsection{Methods}

The analytical protocol was developed by Lebreton [8]. It consists of a hot hydrochloric acid hydrolysis of $1 \mathrm{~g}$ of leaf material dried and ground, causing release of phenolic acids. Exhaustion of the hydrolytic aqueous phase with diethyl ether allows their extraction and assay. From the remaining aqueous phase were extracted the C-glycosides by nbutanol. Spectrophotometry (at $340 \mathrm{~nm}$ ) allows the measurement of C-glycosyl-flavonoids. Results are expressed (in mg.gl MS), as vitexin for C-glycosyl flavonoids. Structural analysis of phenolic acids present in extracts was performed by chromatographic and spectrophotometric techniques. The use of a solvent gradient is more efficient.Regarding the composition of the solvent: acetic acid was chosen, acetonitrile eluent with properties superior to those of methanol has been preferred. The following system:

Solvent A: 0.5\% acetic acid in distilled water;

Solvent B: $0.5 \%$ Acetic acid in acetonitrile.

The linear gradient from $0 \%$ to $20 \% \mathrm{~B}$ in $\mathrm{A}$ in 45 minutes, followed by a return to initial conditions for 15 min with a constant flow of $1.5 \mathrm{~mL} \mathrm{~min}^{-1}$. Detection is at $260 \mathrm{~nm}$.

\section{Results and Discussions}

\subsection{Results of Structural Analysis}

The study of the HPLC profiles of the leaflets of palm trees belonging to the three cultivars studied showed a total of 10 peaks (Fig. 1). Each of these peaks is characterized by its retention time and its absolute content (peak area).

Analysis of all HPLC profiles of phenolic acids is a descriptive work that aims research and differentiation between them, the most original. An original profile is represented by a homogeneous group of plants which combine in the same way all of phenolic acids. Such a profile will be designated by the term "chemotype". Highlighting the different models that are only the expression of status of each cultivar in relation to Fusariosis. We reported on the Table 1, the absolute content mean for each phenolic acid present on profile of the individuals of the three cultivars studied (GH: Ghars TK: Takerboucht, DN: Deglet Nur).

From the Table 1, authors have established the histogram of each cultivar (Fig. 2).

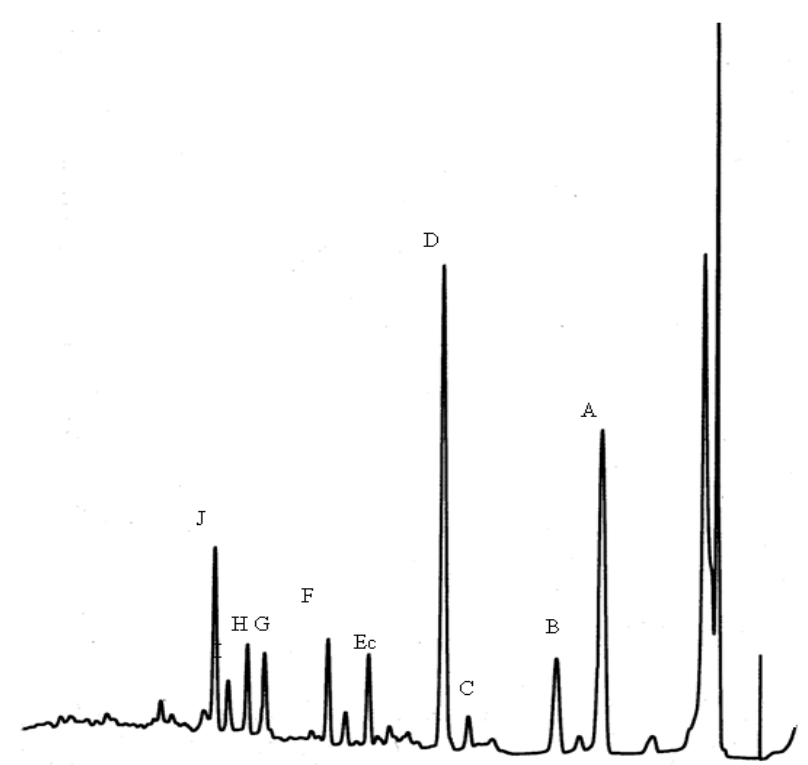

A: Catechol; B: protocatechuic acid; C: gentisic acid; D: parahydroxybenzoic acid; E: vanillic acid; F: caffeic acid; G: syringic acid; H: P. coumaric acid; I: ferulic acid; J: sinapic acid.

Fig. 1 Profile HPLC of phenolic acids of leaflets of the Phoenix dactylifera L. 
Table 1 The absolute content mean for each phenolic acid on profile of the three cultivars studied.

\begin{tabular}{lllllllllll}
\hline & A & B & C & D & E & F & G & H & I & J \\
\hline GH & $14,487.50$ & $1,761.30$ & $15,860.30$ & 72.14 & $5,124.25$ & $1,860.66$ & $3,892.15$ & $1,980.80$ & 90.3 & $36,001.25$ \\
TK & $14,978.21$ & $18,325.30$ & $1,478.04$ & 603.04 & $4,914.10$ & $1,623.20$ & 192.9 & $2,724.80$ & 861.02 & $45,375.74$ \\
DN & $14,978.21$ & $3,741.80$ & $1,577.16$ & 612.22 & $5,243.00$ & $1,636.30$ & 113.16 & $1,443.33$ & 723.53 & $30,210.34$ \\
\hline
\end{tabular}

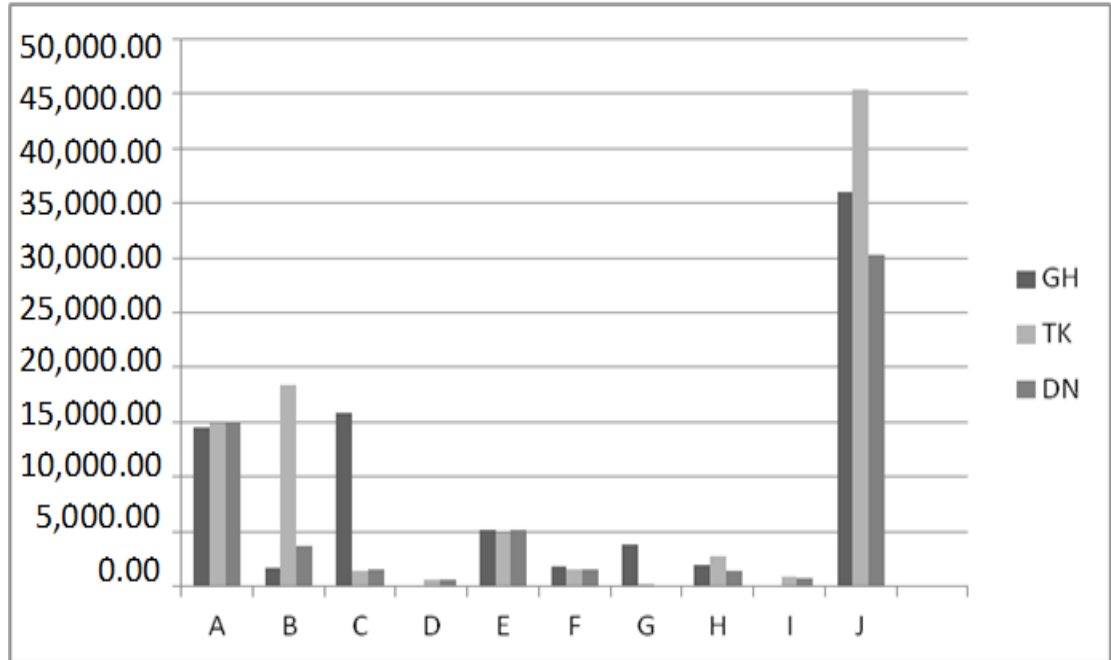

Fig. 2 Histogram established from phenols acid contents.

The Fig. 2 corresponds to chemotypes: resistant with the highest heights (TK: takerboucht). Sensitive (DN: deglet nur), with the lowest height, finally low sensitivity or tolerant (GH: ghars) with intermediate heights.

\subsection{Result of Quantitative Analysis of C-Glycosyl-Flavonoids}

The situation is almost symmetrical to the last, except that changes in these compounds are accompanying the infestation early as before (Table 2), there are increasing (32\%) significantly $(\mathrm{t}=8.30, P<0.001)$.

The increased synthesis of C-glycoflavones, within diseased palms (Fig. 3), can be seen as the first sign of plant response to fungal attack, or even as a defense mechanism so these flavonoids correspond to "pre-inhibitines". It should be noted however that this does not necessarily imply a direct causal relationship, as underlined precisely [9]. In such a context, the increased synthesis of these substances may not be directly related to disease resistance, but may simply be a symptom of the disease.
Table 2 Mean levels of C-Glycosylflavonoids for the cultivars in response to infestation.

\begin{tabular}{|c|c|}
\hline $\begin{array}{ll} & \text { C-glycosylflavonoids } \\
\text { Cultivar } & \end{array}$ & $\begin{array}{l}\text { Mean levels } \\
\left(\mathrm{mg} \mathrm{g}^{-1} \text { M.S.) }\right.\end{array}$ \\
\hline Takerboucht $(\mathrm{n}=10)$ & $3.46+/-0.19$ \\
\hline Deglet nur healthy $(\mathrm{n}=10)$ & $2.49+/-0.22$ \\
\hline Deglet nur diseased $(n=10)$ & $2.98+/-0.25$ \\
\hline Ghars (n = 10) & $3.32+/-0.21$ \\
\hline
\end{tabular}

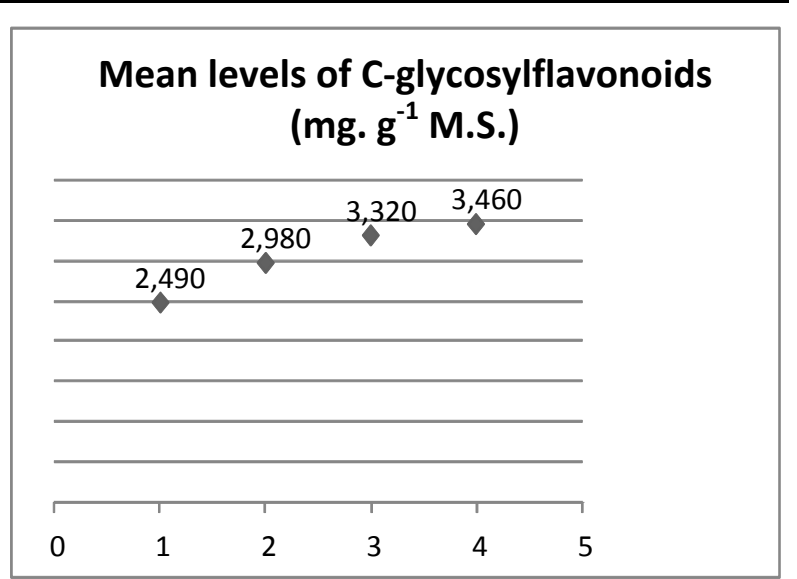

Fig. 3 Increased mean levels of C-glycosyl flavonoids in response to fungal infestation.

\subsection{Modelling Results}

Chemical processes of defense can also be coupled with physical mechanisms, including alteration of 


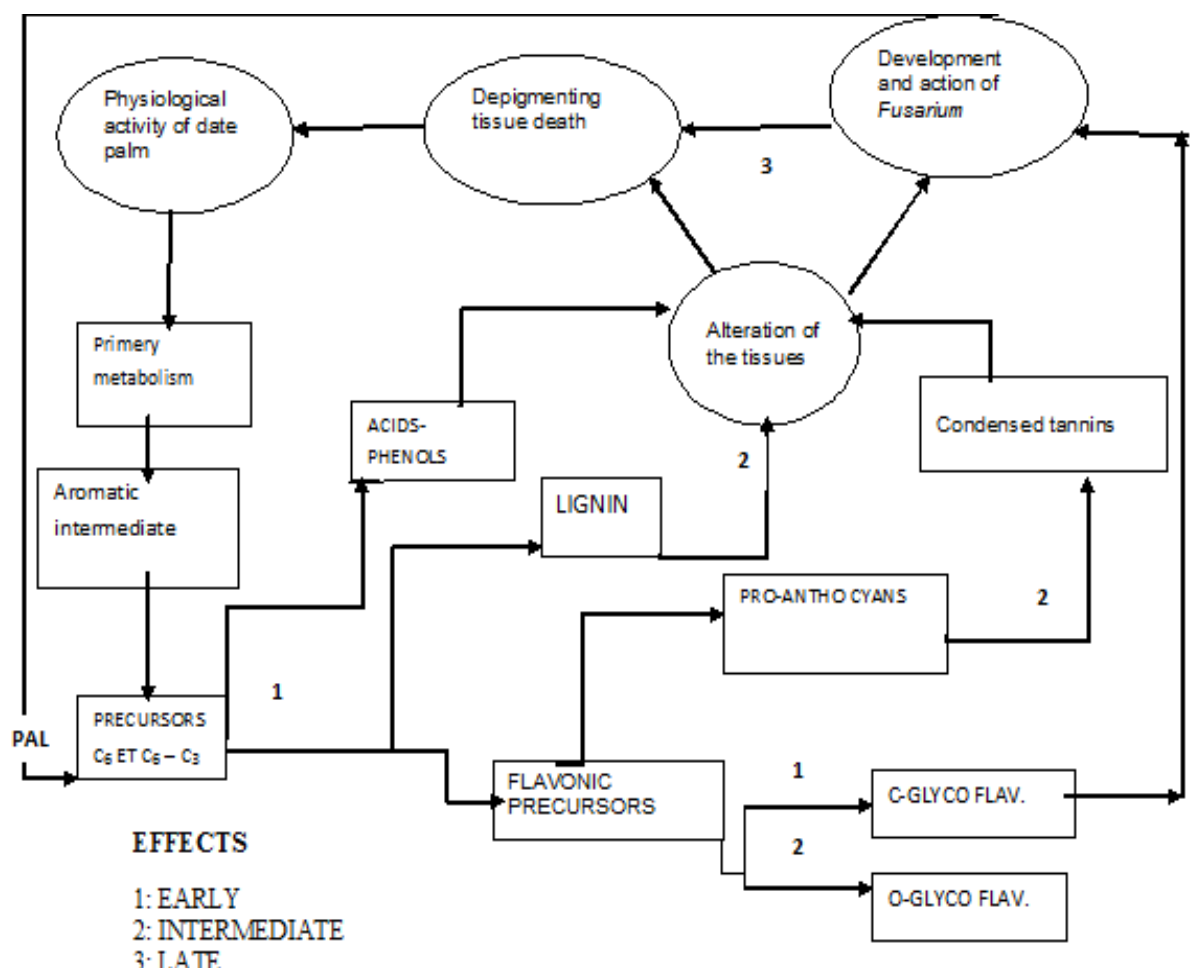

Fig. 4 Diagram representing the impact of Fusarium on the metabolism of date palm.

the vessels, previously reported, the deposits of lignin and/or tannins.This effect opposes to the propagation of Fusarium, but also a double-edged sword in that the diffusion of nutrients and metabolites is also affected. The parasite attack is generally recognized at least in part, the phenomenon may be related to increased activity of PAL (phenylalanine ammonia-lyase), which controls the flow of the amino acid to cinnamic acids, common precursors of phenolic acids, flavonoids and lignin (Fig. 4).

Perhaps the difference in sensitivity to the parasite expressed by the various cultivars of date palm results in the rate of balance achieved between the two channels respectively, positive (1) and negative (2) for the plant.

\section{Conclusion}

In conclusion, it has not been found qualitative differences between different cultivars studied. These were distinguished by their content of different phenolic constituents. The quantitative aspect could therefore be used in the behavior of date palm cultivar in relation to the bayoud. Thus, resistant genotypes accumulate significantly higher level of phenolic acids and C-glycosylflavonoids in leaflets. The criteria could serve as a biochemical marker of date palm resistance to Fusarium oxysporum fsp albedinis. These phenolic compounds are often used in relation to plant pathology in several plant species. Especially some are precursors of lignin. The merits of our work show a negative correlation between flavonoids content and the level of lignification in the date palm suggests that the process of lignification is more rapid in resistant cultivars; we can say that there is a constitutive resistance.

\section{References}

[1] P. Malençon, Les palmeraies du Draa et Bayoud, Bull. Soc. Hist. Nat. Afr. N. 25 (1934) 112-117.

[2] F. Rahmania, Contribution à la connaissance du palmier dattier, (Phoenix dactylifera L.), et de l'agent du bayoud, fusarium oxysporum f.sp. albedinis (Killian et Maire), 

Date Palm Leaflets, Resistant and Sensitive to the Disease

Gordon, Aspects ltrastructuraux des relations Hôte-parasite, Ph.D. USTHB, Alger, 1982.

[3] B. Matheron, A. Benbadis, Etude comparée des premières phrases del'infection du palmier dattier (Phoenix dactylifera L.) par deux formes spéciales de Fusarium oxysporum La f.sp. albedinis (agent du Bayoud) et la f.sp. melonis, Bull. Soc. Fr. 132 (1985) 203-212.

[4] S. Ouafi, Etude chimiotaxinomique par les flavonoïdes des cultivars de palmiers Dattier de la station de l'INRA de ADRAR, Thèse de Magister, USTHB, 1987, p. 125.

[5] S. Ouafi, R. Gaceb Terrak, N. Bounaga, Ph. Lebreton, Les flavonoïdes marqueurs infraspécifiques chez le palmier dattier Phoenix dactylifera L. C.R. Acad, Sci.
Paris 306 (3) (1988) 399-404.

[6] S. Ouafi, N. Bounaga, Les glycosides flavoniques marqueurs de cultivars algériens du palmier dattier Phoenix dactylifera L., Acta Botanica Gallica 155 (2) (2008) 307-315.

[7] S. Ouafi, Les composés phénoliques des folioles du Phoenix dactylifera, UE, 2011, ISBN-10: 6131573484 ISBN-13: 978-6131573484.

[8] Ph. Lebreton, M. Jay, B. Voirin, M.P. Bouchez, Sur l'analyse qualitative et quantitative des flavonoïdes, Chimie Analytique 49 (7) (1967) 375-383.

[9] J.B. Harborne, Flavonoïds and the evolution of the Angiosperms, Biochem. Syst. Ecol. 5 (1) (1977) 7-22. 